\title{
What drives the location choice for water sensitive infrastructure in Melbourne, Australia?
}

Martijn KULLER $^{\mathrm{a} *}$, Peter M. BACH ${ }^{\mathrm{a}, \mathrm{d}, \mathrm{e}}$, Diego RAMIREZ-LOVERING ${ }^{\mathrm{b}}$, Ana DELETIC $^{\mathrm{a}, \mathrm{c}}$

${ }^{a}$ Monash Infrastructure Research Institute, Department of Civil Engineering, Building 60,

Monash University Clayton 3800 VIC, Australia

${ }^{\mathrm{b}}$ Monash Art Design and Architecture, Department of Architecture, Building F, Monash

University, Caulfield East 3145 VIC, Australia

${ }^{\mathrm{c}}$ School of Civil and Environmental Engineering, University of New South Wales Sydney,

Australia 2052

${ }^{\mathrm{d}}$ Swiss Federal Institute of Aquatic Science \& Technology (Eawag), Überlandstrasse 133, 8600 Dübendorf, Switzerland

e Institute of Environmental Engineering, ETH Zürich, 8093, Zürich, Switzerland

*Corresponding author. Tel: +61 481091609, email: martijnkuller@ gmail.com, peter.bach@monash.edu,_diego.ramirez@monash.edu, ana.deletic@monash.edu

This document is the accepted manuscript version of the following article:

Kuller, M., Bach, P. M., Ramirez-Lovering, D., \& Deletic, A. (2018). What drives the location choice for water sensitive infrastructure in Melbourne, Australia? Landscape and Urban Planning, 175, 92-101. https://doi.org/10.1016/j.1andurbplan.2018.03.018 


\section{Highlights}

- We analysed one of the most extensive Water Sensitive Urban Design geo-databases

- Biophysical and urban form-, but not socio-economic factors drive WSUD placement

- Distance to metropolitan centre and age of development drive WSUD abundance

- Wetlands are most prominent in Melbourne, followed by raingardens and ponds \& lakes

- WSUD planning critically needs improved asset inventory development moving forward 


\begin{abstract}
Distributed and green urban drainage infrastructure known as Water Sensitive Urban Design (WSUD) is increasingly being implemented in cities globally to combat climate change and urbanisation effects. Rigorous consideration of the urban context in terms of biophysical, socio-economic and urban form related factors is crucial for optimal design outcomes. The extent to which the urban context is considered in current planning and decision-making processes remains unclear. This study investigates this relationship between current WSUD infrastructure in Melbourne (Australia) and each of the aforementioned factors for the first time. We obtained and pre-processed one of the most extensive and complete geo-located WSUD asset databases in the world (containing over 2,000 WSUD assets), and undertook an evidence-based analysis of WSUD planning outcomes. Relationships were investigated using spatial analysis techniques (e.g. overlaying), as well as a number of statistical methods (e.g. exploratory regression). It was found that biophysical and urban form factors strongly explained variability in WSUD location choice, while socio-economic factors appeared to be overlooked. Our findings imply that the current WSUD planning practices are primarily governed by standard engineering design. Opportunistic WSUD planning leads to unintentional outcomes that fail to capitalise on the full potential of WSUD benefits. Increased investment in asset inventory development and analysis is critical to inform WSUD planning moving forward. Knowledge gained from this and additional studies can further planning through application in planning-support systems, to deal with the complexity and diversity of the broad set of decision criteria.
\end{abstract}

Keywords: Water Sensitive Urban Design (WSUD), Low Impact Development (LID), Sustainable Urban Drainage Systems (SUDS), Urban Planning, spatial analysis 


\section{$1 \quad 1$ Introduction}

2 Water Sensitive Urban Design (WSUD) refers to the introduction of distributed 'green'

3 technologies in the urban landscape for stormwater treatment, detention and reuse with the

4 primary aim to protect and restore natural waterways, decrease the risk and severity of floods

5 and diversify sources of water supply (Dietz, 2007; Wong and Brown, 2009; Woods Ballard

6 et al., 2007). This innovative approach to water management and similar concepts (e.g. Low

7 Impact Development (LID), Sustainable Urban Drainage Systems (SUDS) and Best

8 Management Practice (BMP)) are increasingly being implemented around the world as a

9 strategy to adapt to the pressures of increasing urbanisation and climate change on urban

10 water management (Fletcher et al., 2014; Wong and Brown, 2009). Aside from the

11 abovementioned benefits, WSUD serves a broader set of functions, such as increasing the aesthetic value of neighbourhoods (Backhaus and Fryd, 2013; Dobbie and Green, 2013),

13 providing recreational space (Dobbie and Green, 2013; Wong and Brown, 2009), mitigating

14 urban heat island effects (Coutts et al., 2012; Mitchell and Cleugh, 2006; Steeneveld et al.,

15 2014), and educating communities about urban sustainability (Lundy and Wade, 2011; Rijke et al., 2008). WSUD is a relatively young addition to urban planning practice and although technical design guidelines have been developed, rigorous and experience-based information on the relationship between urban planning and water management is lacking (Sharma et al., 2012). Anecdotal evidence from municipal planning practitioners suggests that WSUD practice has predominantly been driven by 'opportunistic' approaches in both infill developments (retrofitting rain gardens in road renewal sites), or greenfield developments (leaving WSUD integration as the last planning consideration), which may result in less than optimal planning outcomes (Allan, S., personal communication, 1 September 2015; Innes, S.,

24 personal communication, 23 October 2015; Chaffin et al., 2016; Fronteira et al., 2014). WSUD implementation and management guidelines necessary to prevent such opportunistic 
approaches are scarce (Roy et al., 2008) and largely issued on local (municipal) scale. Only for new (greenfield) developments is centralised regulation present (DELWP, 2017).

A growing body of literature reports on the factors that determine the 'suitability' of a location for WSUD implementation (e.g. Ashley et al., 2004; Ellis et al., 2004; Martin et al., 2007; Scholz, 2006). Traditionally, various abiotic (non-biological) biophysical factors (hereafter simply referred to as 'biophysical') are considered for design and placement of WSUD and stipulated in guidelines (e.g. Melbourne Water, 2005; Woods Ballard et al., 2007), such as hydrology (e.g. rainfall), soil, slope and imperviousness. However, recent literature suggests that a wider variety of spatially variable factors can impact the functioning of these technologies, including socio-economic and urban form (e.g. Barbosa et al., 2012). For example, high public literacy and awareness of the function and benefits of WSUD may improve community acceptance and interaction with WSUD. Such literacy and awareness, in turn, is expected to be more easily attained by communities with high environmental awareness and higher education levels, as is the case for public acceptance of similar green innovations such as water recycling schemes (Dolnicar et al., 2011; Domènech and Saurí, 2010).

Besides suitability, the 'need' for WSUD varies spatially, due to the diverse benefits green technologies offer for storm water quantity, quality and amenity (Ashley et al., 2013; Marlow et al., 2013; Wong and Brown, 2009). For example, neighbourhoods with low levels of greenery significantly benefit from the introduction of WSUD, while relatively pristine waterways benefit more from pollution mitigation than degraded waterways (Walsh et al., 2005). Public exposure to WSUD is high in frequently visited open spaces such as train 
process to consider a wide variety of factors. Opportunistic planning approaches overlook these factors, reducing the benefits obtained from WSUD (Schifman et al., 2017).

Growing knowledge about 'suitability factors' is accompanied by a growing number of planning support tools for WSUD. Various planning frameworks incorporate some form of suitability assessment based on multiple factors/criteria (e.g. Jin et al., 2006; Lee et al., 2012). Although these tools predominantly focus on biophysical factors, there is an encouraging trend towards incorporation of a wider variety of aspects, including socio-economic factors (e.g. E2STORMED, 2015; Fronteira et al., 2014; Viavattene et al., 2008). Application of such tools and frameworks could drastically improve planning practices without overly increasing their complexity (Geertman and Stillwell, 2004; Lee et al., 2012; Vonk et al., 2005). Nevertheless, currently available planning-support systems remain underused for a number of reasons including lack of relevance and user-friendliness (te Brömmelstroet and Bertolini, 2008; Vonk et al., 2005). This raises the question to what extent biophysical, socio-economic and urban form factors have been guiding planners' decision-making processes to date.

However, no structured investigation has been conducted to examine location choices for WSUD in metropolitan regions, assessing the impacts of the abovementioned factors. The difficulty of acquiring data on the location, type and size of WSUD assets for an entire metropolitan region may underlie this scarcity. However, this information is crucial in WSUD planning and applications. To understand how the complex urban context impacts the current practice of WSUD planning, the present study aims to characterise WSUD composition (i.e. choice of technology type) and distribution in relation to the urban context for metropolitan Melbourne (Australia). More specifically, we focus on: 
(1) exploring Melbourne's current WSUD inventory in terms of types, land uptake and service area,

(2) investigating relationships between WSUD location and the urban context in terms of biophysical, socio-economic and urban form factors,

(3) assessing to what extent the current practice aligns with WSUD planning best practice as informed by local and current national guidelines

We hypothesise that biophysical factors consistently and strongly drive location choices for WSUD, as they can prohibit their implementation. We would also expect WSUD to be often present in relatively flat areas (as prescribed by design guidelines, e.g. Melbourne Water, 2005) and close to waterways (as WSUD in Melbourne is traditionally driven by the water authority, which is in charge of the larger urban waterways: Brown and Clarke, 2007). Furthermore, we hypothesise socio-economic factors to be weakly related to the locations of WSUD. While socio-economic factors aren't prohibitive to implementation of WSUD, they can decrease its feasibility (CRCWSC, 2014). In contrast, urban form factors are expected to significantly relate to the locations of WSUD. For example, areas of high-intensity land-uses (e.g. commercial centres, high density residential) are space constrained and should therefore include smaller WSUD assets.

To the author's knowledge, this is the first systematic analysis of a geo-located WSUD dataset, using one of the most extensive and complete inventories currently available. Furthermore, for the first time the relationship between a wide variety of spatially variable factors are compared to WSUD placement. In doing so, it increases our understanding on how the complex urban context impacts the current practice of WSUD planning. Lessons from this study are vital to move WSUD planning away from opportunistic practices. 
$100 \quad 2.1 \quad$ Data collection and preparation

101 Melbourne is a rapidly growing city and currently houses 4.5 million residents, making it the second largest city in Australia. It is a sprawled city (i.e. 'low-density expansion of large urban areas, under market conditions, mainly into the surrounding agricultural areas' - EEA, 2006: page 6), similar to others across the country (Coffee et al., 2016; McLoughlin, 1991),

105 North America and, increasingly, also Europe (Batty et al., 2003). It was selected as our case 106 study for its comparatively large experience with the implementation of WSUD (Ferguson et 107 al., 2013) and the availability of a unique, georeferenced, metropolitan-wide WSUD asset 108 database.

\subsubsection{WSUD data acquisition and pre-processing}

111 Melbourne Water, the local water authority, undertook an extensive mapping study of all

112 WSUD assets in 2012, which was collated into a spatial database. The database only includes 113 assets that are primarily built as stormwater management structures, thereby excluding other

114 structures that have an impact on stormwater management (sometimes referred to as 'passive

115 systems', such as lawns and ponds). The assets in the database are managed by different 116 parties, including the local water authority (for assets with a catchment of over 60 hectares -

117 Melbourne Water, 2017), local government and private parties. The scattered nature of

118 management responsibilities is reflected in the scattered nature of data on the distribution of

119 WSUD assets. Although the database contains significant imperfections in terms of accuracy

120 and completeness, this database is one of the most extensive spatial databases of

121 decentralised stormwater infrastructure in the world, and was therefore used in our study. In total, 2,018 WSUD assets were compiled (as a GIS point shapefile), including information

123 about type, geolocation, address, year of construction, size (area) and asset ownership. 
124 Although many additional WSUD assets have since been constructed (Melbourne Water, 125 2013), no further updates were made to this database. Therefore, we adopted the base year for 126 our analysis as 2012 (i.e. the most recent year included in the database).

128 Two of the most crucial shortcomings of the raw database were: incorrect geo-locations and 129 missing data on asset sizes. To remove these inaccuracies and complete the information, we 130 invested considerable effort in verifying the entries and infilling the missing data into the

131 original database. Missing information was sourced through contacting local councils,

132 retrieving satellite imagery and conducting numerous site visits. Thus, the fraction of WSUD

133 assets without size information was reduced to under $10 \%$. All remaining missing system

134 sizes were subsequently estimated, using median system sizes based on type and general 135 location (classified as inner city, middle suburbs and outer suburbs) according to Buxton and 136 Tieman (2005).

138 After cleaning, the database contained complete and verified information on 2,051 WSUD 139 assets from 5 WSUD types: (1) Box/Pit, including planter box rain gardens and tree pits, (2)

140 Rain gardens, including all other types of rain gardens and bio-retention systems, (3) Swales, 141 vegetated drainage ditches, (4) Ponds \& Lakes, containing all constructed open water bodies 142 and (5) Wetlands, containing all constructed wetland systems.

$144 \quad$ 2.1.2 Collection of urban biophysical, socio-economic and urban form data

145 We collected data on biophysical, socio-economic and urban form as our independent

146 variables. The selection of these variables (summarised in Table 1) was based on availability

147 and relevance. The included biophysical factors, surface slope and distance from natural 
148 waterways, are regularly considered in design (Melbourne Water, 2005; Woods Ballard et al.,

149 2007) and suitability analyses of WSUD (e.g. Jin et al., 2006; Lee et al., 2012).

150

151 Socio-economic factors such as environmental awareness and related acceptance (e.g.

152 Sharma et al., 2012; Thompson and Maginn, 2012; Wong and Brown, 2009), and education

153 level (e.g. Chiesura, 2004; Lovell and Taylor, 2013; Mell, 2009) have been identified by the

154 scientific literature as potentially impactful. IRSAD and IER are census-based indicators

155 measuring aspects of socio-economic advantage and disadvantage, developed by the

156 Australian Bureau of Statistics (ABS, 2013). While the former provides a rank of overall

157 socio-economic advantage and disadvantage, the latter focuses on the financial aspect of

158 relative advantage/disadvantage. Detailed information on these indicators can be found in

159 ABS (2013). We included a 'heat vulnerability index' (Loughnan et al., 2012) in our analysis,

160 considering the mitigating effects of WSUD on urban heat islands (e.g. Ahern, 2013; Bolund

161 and Hunhammar, 1999; Lovell and Taylor, 2013). Scarcity of indicator data posed a barrier to

162 the inclusion of socio-economic factors. To overcome this barrier, the use of proxy variables,

163 describing phenomena which cannot be directly measured or for which data cannot be

164 obtained, is common practice in social sciences (e.g. Montgomery et al., 2000). We

165 represented 'environmental awareness' and 'sense of community' with the proxies 'first

166 preference votes for The Greens in federal elections' and 'people engaging in voluntary work

167 for a local organisation or group', respectively (see Table 1). Despite the inherent limitations

168 related to the use of proxies, direct measurement of these indicators fell outside the scope of

169 this study.

170

171 Finally, urban form factors describe artificial planning and urban landscape characteristics

172 such as land use and location of assets. They were expressed either in relation to the general 
173 city structure or in relation to nearby features such as streets. A water-centric land-use

174 classification detailed by Bach et al. (2015) was used for this analysis. As urban form

175 changes with distance to the centre in a sprawling city such as Melbourne (Galster et al., 2001;

176 McLoughlin, 1991), this factor was also investigated. Special attention was given to the

177 presence (relative quantity and size) of WSUD in 'streetscapes', as a crucial subtype of the

178 urban landscape. These are all public open spaces around roads and streets, which hold a

179 special position because of their prominence in people's day-to-day experience of the city. As

180 urban form factors are primarily concerned with WSUD appearance and integration in the

181 landscape (including characteristics such as shape and size), we focussed our analysis on

182 WSUD land uptake: the amount of space taken up by an asset and its distribution across land

183 uses, rather than the asset's service provision.

184 
INSERT TABLE 1

186

187

\subsubsection{WSUD data preparation}

188 We distinguished between two types of urban factors data: (1) spatially explicit data, which included biophysical and urban form factors and (2) non-spatially explicit data, which contained all socio-economic factors. The second type of data cannot be directly spatially analysed (due to its aggregated nature). Therefore, we defined a metric that aggregates WSUD data over a geographic unit (suburbs): Relative WSUD (RW). RW is dimensionless, and represents the fraction of a geographic unit's impervious surface stormwater runoff that is serviced by WSUD. RW typically varies between 0 (no impervious area serviced by WSUD) and 1 (all impervious areas serviced by WSUD). RW values occasionally exceed 1, as WSUD can treat upstream areas outside the geographic unit under consideration. RW allowed us to normalise the WSUD data set against varying rainfall pattern, asset type and connected impervious area. It was calculated as follows:

199

$$
R W_{j}=\sum_{i=1}^{n} \frac{A_{i}}{\theta_{i}\left(e_{j} A_{j}\right) \times \alpha_{i j}}
$$

200 where $R W_{j}$ is Relative WSUD in geographic unit $j$ (in our case suburb), $\theta_{i}$ indicates WSUD

201 size relative to serviced impervious area, $A_{i}$ is the area of WSUD asset $i, \alpha_{i j}$ the adjustment factor for technology $i$, used to adjust for differences between rainfall patterns and geography of geographic unit $j$ (in some cases derived from a function, see equation 2 ), $e_{j}$ is the impervious fraction of geographic unit $j, A_{j}$ is the area of geographic unit $j, n$ is the number of assets in geographic unit $j$. Metropolitan Melbourne is divided into four rainfall regions, defined by $\alpha_{i j}$ : 


$$
\alpha_{i j}=\beta_{t j}\left(M A R_{j}\right) \times \gamma_{t j}
$$

207 where $\beta_{t j}$ and $\gamma_{t j}$ are adjustment factors depending on WSUD type $t$ and geographic unit $j$ (the

208 reader is referred to chapter 2 of 'WSUD engineering procedures' for the values of $\beta_{t j}$ and $\gamma_{t j}$ -

209 (Melbourne Water, 2005)), and $M A R_{j}$ is the mean annual rainfall in geographic unit $j$

210 (Melbourne Water, 2005).

\subsection{Data analysis}

\section{$213 \quad 2.2 .1 \quad$ Spatial analysis}

214 All the spatial analyses were performed using the ESRI spatial software ArcMap. We

215 analysed biophysical and urban form factors by overlaying the WSUD database with these

216 datasets. We then compared the results to Melbourne's 'typical' (median) values, which were

217 obtained using a Monte Carlo method. In total, 200,000 random points (approx. $100 \mathrm{x}$ the

218 number of WSUD assets) were sampled across our spatial domain to determine a 'typical'

219 distribution of slope and waterway distance. As convergence occurred for both factors, we

220 deemed the sample size to be sufficiently large. The distance to the geographic centre of

221 Melbourne was calculated using the geographic centre (centroid) of the four inner-city

222 councils as our datum. We identified this point using the definition of inner-city councils

223 proposed by Buxton and Tieman (2005).

225 For 'Land use', the number and land uptake of WSUD assets were analysed per land-use

226 category to determine trends in the distribution of WSUD. Streetscapes, as a subtype of urban

227 landscapes, received additional attention in our analysis. We statistically compared the

228 abundance of streetscapes to the abundance (land uptake and serviced area) of WSUD located in streetscapes to see if WSUD was overrepresented. 


\subsubsection{Statistical analyses}

232 We conducted three stages of statistical analyses on the socio-economic factors to examine 233 potential interrelationships with WSUD planning:

234

235 Simple correlation analysis

236 We determined correlations and cross-correlations using a correlation matrix in the statistical

237 software SPSS. The normality assumption could not be verified, as a third of suburbs had an 238 RW value of 0. Therefore, we used the Spearman's rho correlation coefficient, which is the 239 non-parametric version of the standard Pearson correlation coefficient, and can overcome the 240 issue of non-normally distributed data sets (Myers et al., 2010).

242 Evaluating relationships

243 We applied three techniques to further investigate relationships, as strong cross-correlations 244 between nearly all factors were initially found. This pointed to a single factor that drove all 245 cross-correlations and, thus, required normalisation. Exploratory spatial regression, stepwise 246 regression and Principle Component Analysis (PCA) were performed on the data. We

247 organised our data against four different definitions of the metropolitan region boundaries to 248 account for the effect of Melbourne's unsymmetrical sprawl (Beed, 1981; Department of 249 Infrastructure, 1998): (1) all urban and peri-urban suburbs, (2) exclusion of suburbs of 'rural'

250 councils, (3) elimination of suburbs with a population density of under $500 \mathrm{p} / \mathrm{km}^{2}$ and (4)

251 elimination of 'fringe' suburbs, further than $30 \mathrm{~km}$ from the geographic urban centre (as 252 defined previously). 
254 Exploratory spatial regression is the process of generating several regression models that include one, two, or up to any number of factors (Rosenshein and Scott, 2011). This iterative process consecutively eliminates the worst performing factor in terms of explanatory power (\% of explored models in which the factor was selected) and consistency (tendency towards either a positive or negative relationship to the dependent variable). This method was applied using ArcMap's 'exploratory regression tool', to select the best performing proxy for factors that can be represented by several proxies (e.g. the fraction of people with a bachelor degree outperformed school diploma and postgraduate degree as a proxy for education level).

Furthermore, it showed that there was little gain in including more than one factor in the regression model, pointing towards a single variable driving all cross-correlations.

To improve our confidence in the analysis, we cross-checked these findings through stepwise regression and Principle Component Analysis (PCA), using the statistical software SPSS. In our analysis, each suburb average represented one data point. Stepwise regression is an automated process that includes and excludes predictors based on the t-statistic of their estimated coefficients (Draper and Smith, 2014). PCA is a technique for dimension reduction developed by Hotelling (1933), where the eigenvectors of all factors are projected on a lower, and in our case 2-dimensional frame. The eigenvectors that are most aligned with the dependent variable (RW) and with the highest eigenvalue (i.e. longest vectors) have the

273 highest predictive power. Both analyses confirmed the existence of a single dominating 274 variable.

Correlation analysis of data subsets

277 We normalised our dataset for distance to centre as a potential single dominating variable, 278 representing the relative location of a region in the metropolitan area. We used the second 
279 definition of the metropolitan boundaries described earlier in this paragraph: eliminating

280 regional councils. We divided Melbourne into spatial 'rings', based on distance to centre.

281 The number of rings was determined through stepwise addition of classes in the symbology

282 field of the shapefile within ArcMap, until all correlations between RW and distance to

283 centre were removed. We used Jenks natural breaks classification method, which seeks to

284 minimise variance within classes while maximising it between them (Jenks, 1967). Five rings

285 (as opposed to the three rings used by Buxton and Tieman (2005)) were found to be the

286 minimum necessary to remove the influence of the distance to centre with RW. Rings were

287 given the following names from low to high distance to centre: (a) central (b) inner suburbs

288 (c) middle suburbs (d) outer suburbs (e) fringe.

290 To investigate the relationships between each factor and RW, we repeated the simple

291 correlation analysis for each ring individually, following the data normalisation and division

292 into subsets, based on the five selected rings of Metropolitan Melbourne.

\section{Results \& Discussion}

$294 \quad 3.1 \quad$ Descriptive statistics

295 The distribution, number, land uptake and service area of the various WSUD assets in the

296 Melbourne metropolitan area are shown in Figure 1. Comparisons between system numbers,

297 sizes and serviced area revealed their level of 'compactness'; rain gardens represent $30 \%$ of 298 the number of WSUD assets, $17.3 \%$ of service area but only $8.4 \%$ of the total land uptake by

299 WSUD in Melbourne, reflecting their compact size. In contrast, wetlands have a 26.9\% share

300 in number, $65.5 \%$ share in service area and $62.9 \%$ share in land uptake. This compactness

301 illustrates how various WSUD assets are suited for dense inner-city areas (rain gardens) or

302 sprawling suburbia (wetlands). 

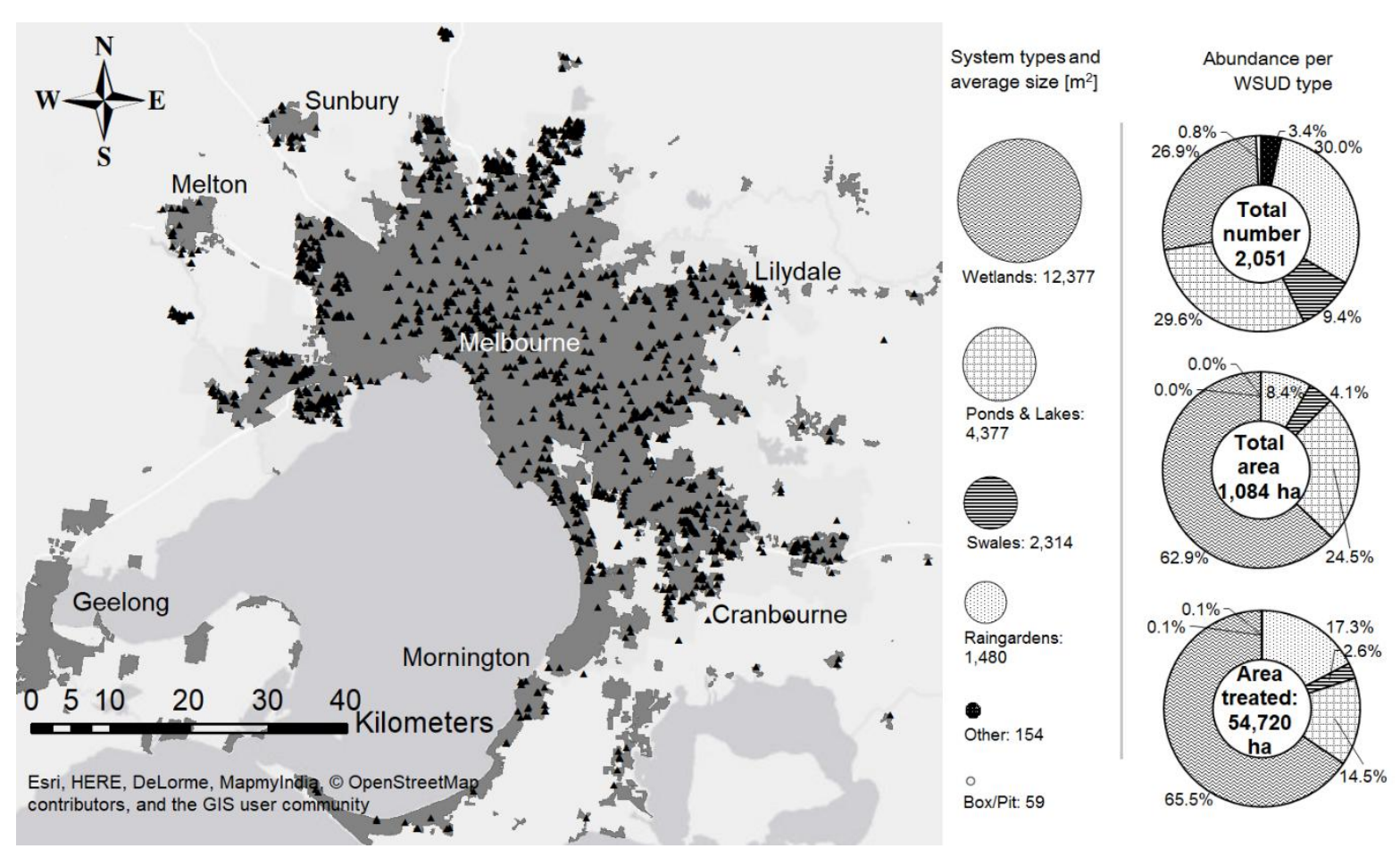

Figure 1 Spatial and typological distribution of WSUD in Melbourne; green rhomboids on the map represent locations of WSUD assets in 2012.

\section{$304 \quad 3.2 \quad$ Biophysical factors}

305 In line with our hypothesis, the observed patterns of WSUD placement suggest an important

306 role for biophysical factors in the location choice for WSUD. WSUD is typically placed on

307 lower slopes (median < 1\%), and rarely on slopes above $5 \%$ (Figure 2), in accordance with

308 design guidelines (Melbourne Water, 2005). While guidelines for placement near waterways

309 are absent, WSUD is placed close to natural waterways - often at the outlet of stormwater

310 drainage systems, capturing and treating runoff from impervious areas in the catchment to

311 protect waterway health (Walsh et al., 2005). This placement towards the end of catchments

312 is unfortunate, as source control within catchments is shown to be more effective than 'end-

313 of-pipe' solutions for pollution control (e.g. Bressy et al., 2012; Walsh et al., 2005) as well as

314 for flood management (Urich et al., 2013). 

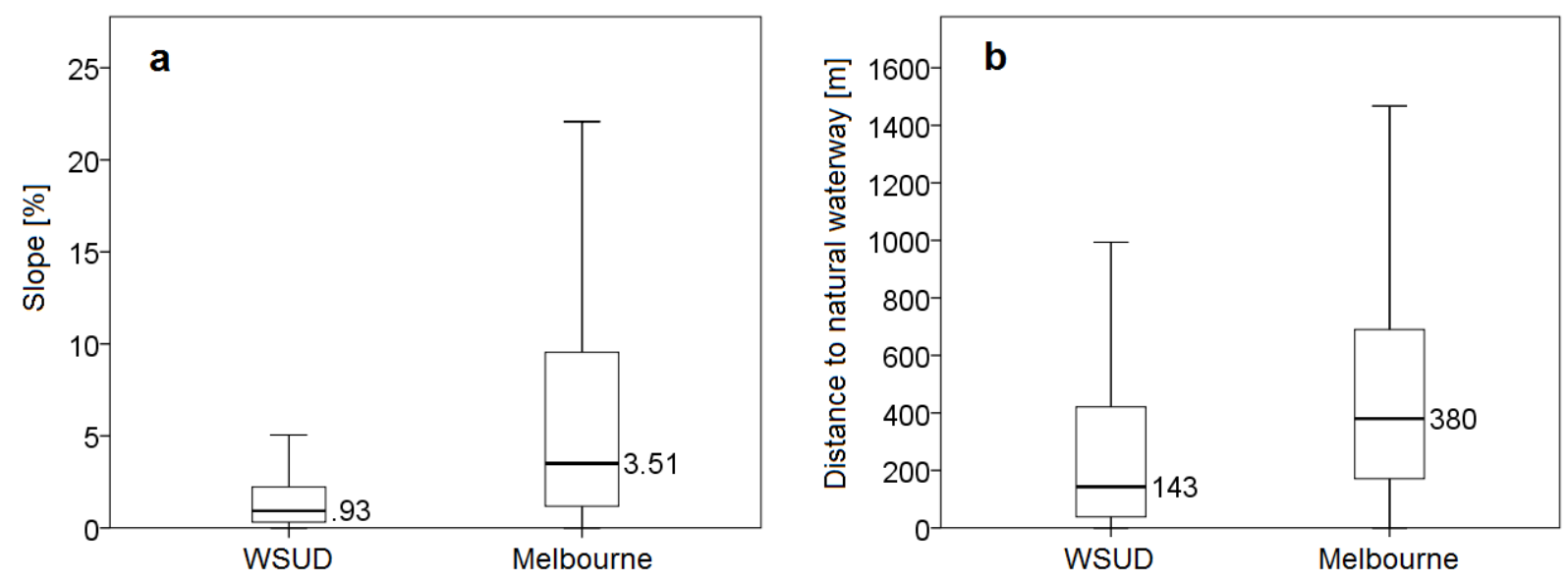

Figure 2 Relation between the (a) slope and (b) distance to natural waterways of WSUD locations, compared to randomly selected Melbourne locations.

\subsection{Socio-Economic factors}

317 Against our hypothesis, all but two socio-economic factors were highly and inversely

318 correlated to RW (except for Index of Economic Resources - IER which is proportional to

319 RW) (Figure 3a). Exceptions are Index of Relative Socio-Economic Advantage and

320 Disadvantage (IRSAD) and Heat Vulnerability, where no correlations were observed (Figure

321 3a). As nearly all factors were cross-correlated, we used stepwise regression (Figure 3b), exploratory spatial regression (Figure 3c) and PCA (Figure A.1, Appendix 1) to investigate relationships. All these techniques pointed towards just two strong predictors for RW:

324 distance to centre and age of development, which are highly correlated to each other (Figure 3b). As these factors were strong predictors for all socio-economic factors as well, normalisation was required.

328 Results show that the predictive strength of distance to centre and age of development

329 depends on the definition of the metropolitan boundary, as Melbourne's sprawl is

330 asymmetrical and historically occurred in south-easterly direction, along major railway lines and highways (Beed, 1981; Department of Infrastructure, 1998) (Figure 4i). During 
332 Melbourne's expansion, the metropolitan area encapsulated existing settlements along its

333 fringes. Therefore, distance to centre performs best when the metropolitan boundary is

334 defined to exclude 'fringe' and 'shire' councils along the urban periphery (i.e. an attempt to

335 symmetrise sprawl - Figure 3b,c). The performance of age of development is more robust

336 against changes in the definition of the metropolitan boundary, but slightly weaker overall.

337

338 Five 'urban ring' subsets of data were acquired after normalisation for distance to centre

339 (Figure 4h), as described in Section 2.2.2. Following normalisation, we found that nearly all

340 correlations between socio-economic factors and RW were eliminated (Table 2). Only in the

341 fringe ring did some correlations remain, potentially caused by the distortion of Melbourne's

342 unsymmetrical sprawl pattern. Several circumstances may explain the relationship between

343 RW and distance to centre. Further from the dense inner city, decreasing urban densities

344 remove space constraints. Cities sprawl from their centre through consecutive addition of

345 urban developments in their fringes, leading to older and more established areas close to the

346 centre (Department of Infrastructure, 1998). Retrofitting in older established areas is more

347 challenging and costly due to a fixed urban context. Therefore, system placement is preferred

348 in less established areas further from the centre. Furthermore, Melbourne's planning

349 regulations prescribe all new greenfield developments to implement WSUD (DPCD, 2016),

350 while requirements for WSUD implementation in infill developments are only present in a

351 small number of jurisdictions. Finally, higher RW in fringe areas aligns with recent insights

352 on stream health protection, prioritising protection of pristine peri-urban catchments

353 (Urrutiaguer et al., 2012). 


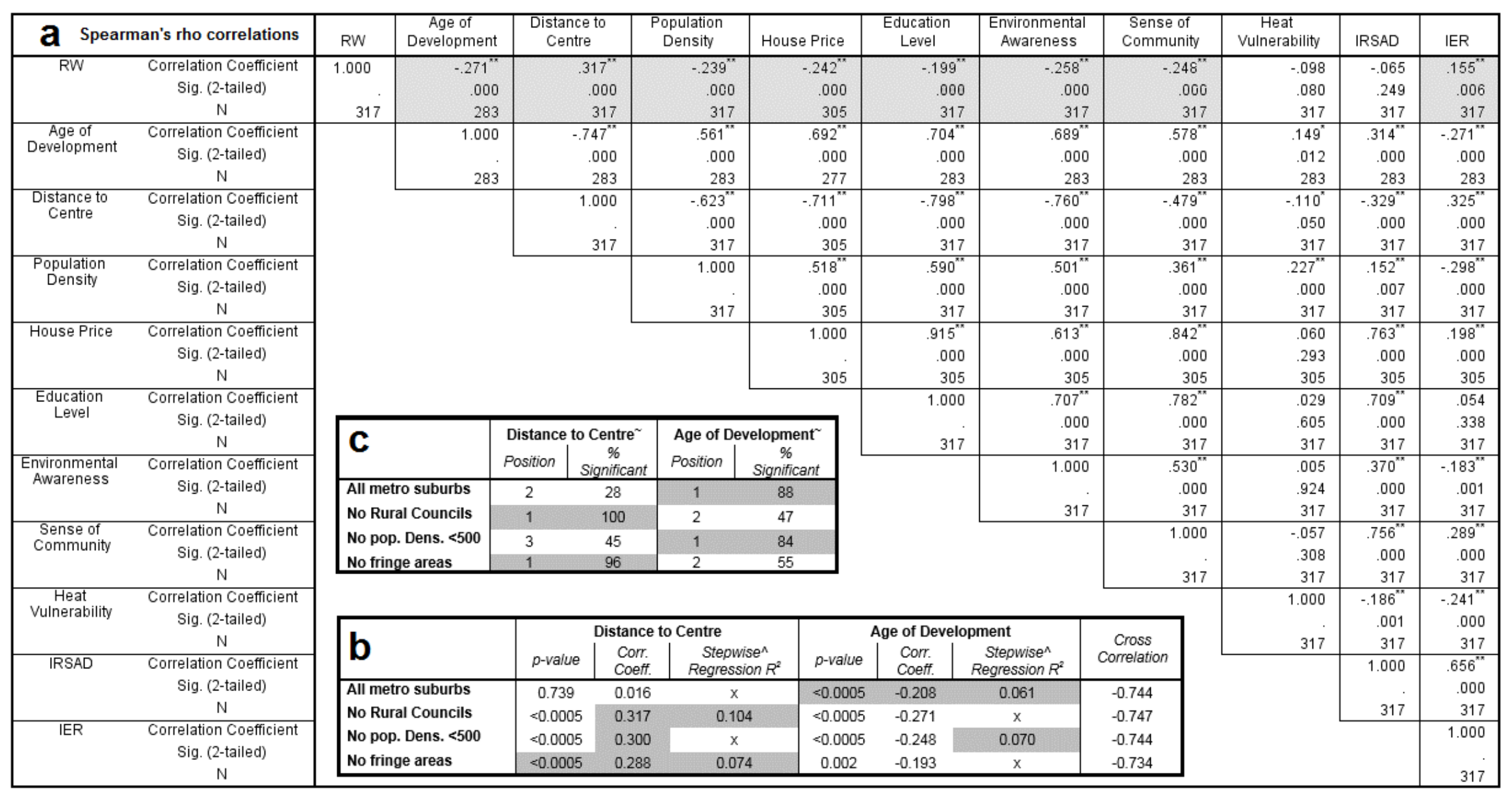

Figure 3 Correlation matrix between RW and all socio-economic factors per suburb, excluding rural councils and (a) comparative performance to predict RW for variables: distance to centre and age of development through correlation and stepwise regression (b) as well as exploratory regression (c).

Shaded cells indicate (a) highly significant correlations between RW and the socio-economic variables, (b,c) outperformance over the other variable

*Correlation is significant at the 0.05 level (2-tailed). ${ }^{* *}$ Correlation is significant at the 0.01 level (2-tailed).

$\wedge$ All four stepwise regressions resulted in a single factor to be selected for the optimal model. 
'Position' indicates the relative strength of the factor compared to the 8 factors used in this exploratory regression, whereas ' $\%$ Significance' indicates the percentages of trials in which this factor was identified a significant contribution to the predictive model. In all trials the direction of the relation $\mathrm{n}$ was consistent (positive for distance to centre and negative for age of development). 
357 These results suggest a tendency for WSUD to be located in communities of relatively low house prices, environmental awareness, sense of community and education level as well as high economic resources, as they tend to be located further from the centre (note: such a city structure is typical for Australian cities; however, this could be different in other parts of the world). Such tendency is most likely unintentional, given the emphasis on physical factors and hydrology in the planning practice (Schifman et al., 2017). A potential lack of understanding and appreciation for WSUD, resulting from low environmental awareness and education levels, may cause a lack of acceptance and intentional and unintentional maltreatment of these assets, jeopardising their operation (Chaffin et al., 2016; Sharma et al., 2012). This highlights the need for investment in human, social and cultural capital through education campaigns about the function and benefit of green infrastructure, to support the uptake and acceptance of WSUD practices among residents. Such investments were proven highly effective for the uptake of rain gardens and rain tanks (Green et al., 2012), and were shown to dramatically increase people's acceptance (Mathey et al., 2015). At the same time, WSUD has the potential to educate communities about the importance of urban water and stream protection, increase a sense of community by serving as a public open space (Dobbie and Green, 2013; Rijke et al., 2008) and increase property prices through their amenity value

374 (Mahan et al., 2000).

375 Our results indicate that socio-economic factors are currently not considered in location planning directly. The disregard of most socio-economic factors may be caused by a lack of

377 knowledge and awareness among planning practitioners. This presumption is reinforced by 378 the low representation of socio-economic criteria in WSUD guidelines and regulations. 

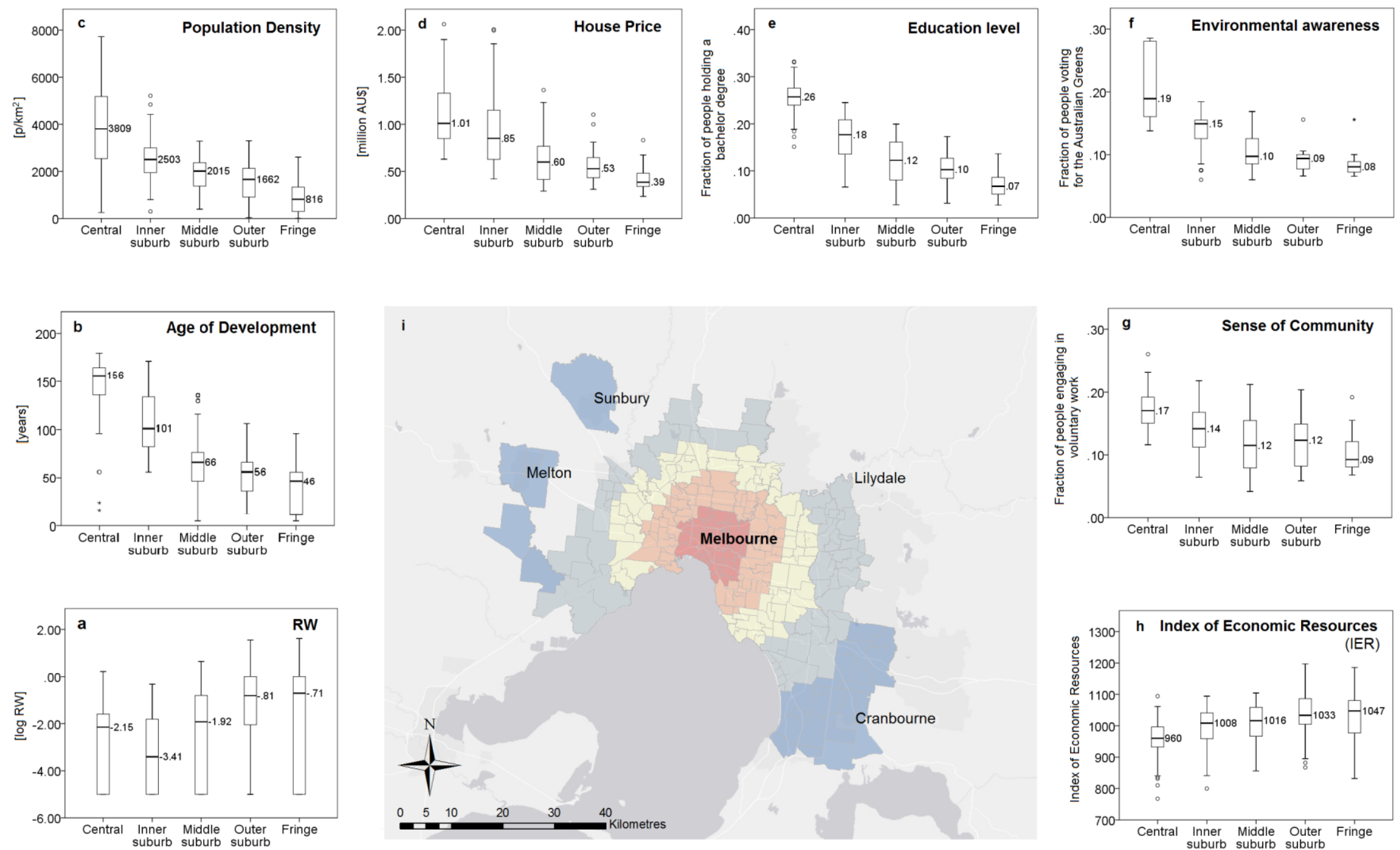

Figure 4 (a): Relationship between distance to centre and RW, (b-h): Relation between the significantly correlating socio-economic factors and distance to centre and (i): Map of central-innermiddle-outer-fringe rings. 


\subsection{Urban form factors}

379 Figure 5 shows that larger WSUD assets tend to be placed further from the city centre,

380 confirming the "design bulls-eye" suggested by Charlesworth (2010). Rain gardens have the

381 most even distribution, pointing to their versatility and flexibility. Very small assets, such as

382 box rain gardens and tree pits, tend to be placed in inner-city areas (Figure 5). Large assets

383 such as ponds, lakes and wetlands are predominantly placed in outer suburbs and fringe areas.

384 Swales sit between these extremes, with the majority of assets situated in middle and outer

385 suburbs. 


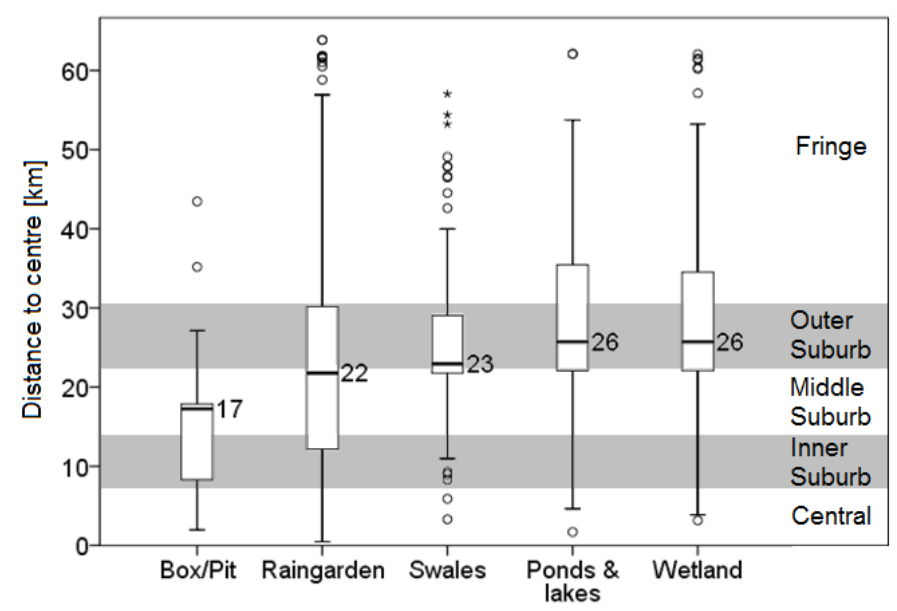

Figure 5 Distribution of WSUD types and their distance to centre, sorted by increasing system mean size.

387 Figure 6a shows the distribution of WSUD in terms of frequency (y-axis) and the total land uptake (x-axis) among different land-use types. It shows us that land uses of high density and public exposure such as 'mixed high-density residential \& commercial', 'low density trade' and 'high density residential' have a high density of very small assets. The exception is 'mixed trade \& industry' where density is low, but system sizes are large. Relatively open and predominantly publicly owned land uses such as 'floodway' and 'service and utility' have many large assets. The exception is 'reserves' where fewer WSUD assets are placed.

394 Some land uses that might benefit most from the educational and amenity benefits of WSUD, i.e. 'education' and 'health and community' (schools, hospitals, libraries etc.) have a low occurrence of assets.

Streetscapes received special attention in our analysis. Quality of streets is at the core of urban productivity, sustainability, quality of life and social inclusion (UN Habitat, 2013).

400 They form a major part of all impervious surfaces in the city and are typically publicly owned. Figure $6 \mathrm{~b}$ shows a heavy overrepresentation of WSUD in Melbourne streetscapes, with over $21 \%$ of all assets representing nearly $15 \%$ of serviced area in this urban landscape, which represents only $6 \%$ of Melbourne area. Assets are relatively small, illustrated by the 
404 difference between the share in number $(21 \%)$ and land uptake $(9 \%)$ of assets. Anecdotal

405 evidence from municipal planning practitioners suggests that opportunistic planning practices

406 may explain the overrepresentation of WSUD in streetscapes, as councils tend to utilise street

407 renewal and roadworks to co-implement assets (e.g. Allan, personal communication, 1

408 September 2015; Innes, personal communication, 23 October 2015).

409

410 These findings are generally in line with our hypothesis. Although urban form factors are not

411 always as prohibitive as some biophysical factors, they are still well understood and

412 thoroughly considered in current urban planning practice. 


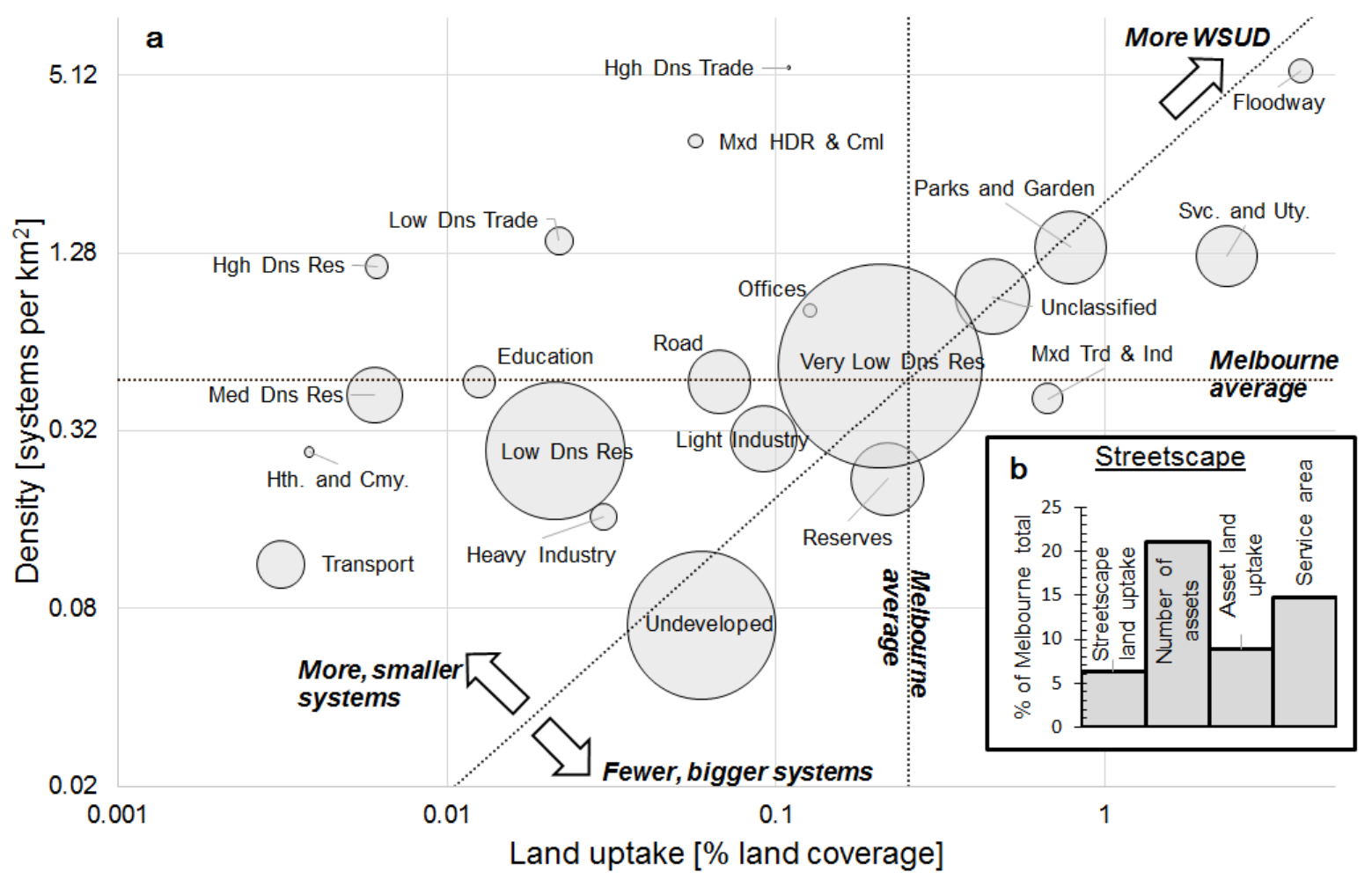

Figure 6 (a) Prominence of WSUD among land-use types in terms of system count (vertical axis) and size (horizontal axis). Each circle represents a land-use type, circle size represents the area of that land-use type in Melbourne. The horizontal and vertical lines represent the average density and land uptake of assets, while the diagonal is the iso-size line at the average system size in Melbourne. (b) Prominence of WSUD in streetscapes.

414 The results of this paper reflect the relatively ad-hoc WSUD planning practices in Melbourne

415 in which certain biophysical and urban form factors are considered, whilst socio-economic

416 factors are largely overlooked. This has, unintentionally, led to an uneven distribution of

417 WSUD systems and their attributed benefits across the Melbourne Metropolitan area. In turn,

418 this results in reduced effectiveness (i.e. optimising benefits and co-benefits).

419 To prevent these undesirable outcomes, strategic WSUD planning practices and tools should

420 be employed, rigorously considering all aspects of the specific urban context, actively

421 involving all relevant stakeholders, and remaining adaptive to an uncertain and ever-changing

422 reality. Such tools and methods are increasingly being adopted by sustainable urban water

423 management practitioners and include, but are not limited to: planning simulators (e.g.

424 SUSTAIN-EPA: Lee et al., 2012), (spatial) multi-criteria decision analysis (e.g. Fronteira et 

promote social and cultural learning (e.g. Shuster W.D. et al., 2008) and experimentation (e.g. Chaffin et al., 2016; Farrelly and Brown, 2011).

\section{Conclusion}

431 This is the first study to systematically investigate the relationships between WSUD

432 distribution and biophysical, socio-economic and urban form factors for a greater

433 metropolitan region. We used one of the most extensive and complete spatial WSUD

434 databases in the world. Despite its status as 'front-runner', the asset data for Melbourne are

435 still imperfect and needs significant levels of engagement. Nevertheless, clear trends could be 436 observed. Numerically, rain gardens, ponds, lakes and wetlands are equally abundant, while 437 wetlands overwhelmingly account for the greatest land-uptake with two-thirds of the WSUD 438 total.

439 The manifestation of WSUD as an integrated part of the urban landscape is reflected by its

440 reciprocal relation with the urban context, as highlighted by our study results. Strong

441 relationships between WSUD distribution and biophysical, socio-economic and urban form

442 factors were revealed. Constraints from biophysical factors as well as urban form underpin

443 WSUD placement; however, socio-economic factors are disregarded. Biophysical

444 circumstances can prohibit WSUD placement, while socio-economic factors seem to have a

445 more accidental, potentially unintended effect. Urban areas that may highly benefit from

446 WSUD may thus be overlooked. Intrinsically interwoven, these three aspects constitute the 447 physical and social fabric of city scapes, which build the stage for WSUD integration. 
449 Melbourne's current policy and guideline frameworks do not prevent ad-hoc and

450 opportunistic planning practices to dictate WSUD placement. Ad-hoc planning does not

451 promote equitable distribution of WSUD. In Melbourne it has led to the overrepresentation of

452 WSUD in communities with low environmental awareness, low education levels and low

453 sense of community, as a result of the specific urban structure.

454

455 To make WSUD successful, it is critical for urban planners to start incorporating a wide

456 variety of biophysical, socio-economic and urban form factors in their decision-making.

457 Currently, we lack understanding of the urban context in relation to WSUD placement,

458 restricting our capacity to increase strategic approaches. This study is a first attempt to

459 address this gap, but increased efforts from government and water authorities/utilities to

460 create and maintain high quality asset inventories are called for. Therefore, recent trends

461 towards more strategic and integrated planning for WSUD are encouraging and have the

462 potential to significantly improve the outcomes of water quality, flood safety and amenity for

463 urban communities.

465 Future research should focus on replication of this work in comparable urban landscapes with

466 WSUD found across Australia and North America, such as the green champion city of

467 Portland in the USA (Netusil et al., 2014), as well as for those in Europe and Asia, where

468 urban growth is governed by different patterns. Including other/more factors is important, as

469 our study is limited and doesn't include important variables such as land. The outcomes of

470 this and future studies should be used to raise awareness among urban planners about the

471 outcomes of their current processes. They call for the development and application of practice 
472 guidelines, strategic approaches and planning support systems that enable integration of a 473 broader set of criteria in addition to biophysical design parameters.

474 


\section{References}

ABS, 2013. Socio-Economic Indexes for Areas (SEIFA). Australian Bureau of Statistics: Canberra (Australia).

Ahern, J., 2013. Urban landscape sustainability and resilience: the promise and challenges of integrating ecology with urban planning and design. Landscape ecology 28(6) 1203-1212. Ashley, R., Booker, N., Smith, H., 2004. Sustainable water services: a procedural guide, First ed. IWA Publishing, London.

Ashley, R., Lundy, L., Ward, S., Shaffer, P., Walker, A.L., Morgan, C., Saul, A., Wong, T.H.F., Moore, S., 2013. Water-sensitive urban design: opportunities for the UK. Proceedings of the Institution of Civil Engineers 166(ME2) 65-76.

Bach, P.M., Staalesen, S., McCarthy, D.T., Deletic, A., 2015. Revisiting land use classification and spatial aggregation for modelling integrated urban water systems. Landscape and Urban Planning 143 43-55.

Backhaus, A., Fryd, O., 2013. The aesthetic performance of urban landscape-based stormwater management systems: a review of twenty projects in Northern Europe. Journal of Landscape Architecture 8(2) 52-63.

Barbosa, A.E., Fernandes, J.N., David, L.M., 2012. Key issues for sustainable urban stormwater management. Water Research 46(20) 6787-6798.

Batty, M., Besussi, E., Chin, N., 2003. Traffic, urban growth and suburban sprawl.

Beed, C.S., 1981. Melbourne's development and planning.

Bolund, P., Hunhammar, S., 1999. Ecosystem services in urban areas. Ecological Economics 29(2) 293-301.

Bressy, A., Gromaire, M.C., Lorgeoux, C., Saad, M., Leroy, F., Chebbo, G., 2012. Towards the determination of an optimal scale for stormwater quality management: Micropollutants in a small residential catchment. Water Research 46(20) 6799-6810.

Brown, R.R., Clarke, J.M., 2007. Transition to water sensitive urban design: The story of Melbourne, Australia. Monash University, Melbourne (Australia).

Buxton, M., Tieman, G., 2005. Patterns of Urban Consolidation in Melbourne: Planning Policy and the Growth of Medium Density Housing. Urban Policy and Research 23(2) 137-157.

Chaffin, B.C., Shuster, W.D., Garmestani, A.S., Furio, B., Albro, S.L., Gardiner, M., Spring, M., Green, O.O., 2016. A tale of two rain gardens: Barriers and bridges to adaptive management of urban stormwater in Cleveland, Ohio. Journal of environmental management 183(Part 2) 431-441.

Charlesworth, S.M., 2010. A review of the adaptation and mitigation of global climate change using sustainable drainage in cities. Journal of Water and Climate Change 1(3) 165-180.

Chiesura, A., 2004. The role of urban parks for the sustainable city. Landscape and Urban Planning 68(1) 129-138.

Coffee, N.T., Lange, J., Baker, E., 2016. Visualising 30 Years of Population Density Change in Australia's Major Capital Cities. Australian Geographer 47(4) 511-525.

Coutts, A.M., Tapper, N.J., Beringer, J., Loughnan, M., Demuzere, M., 2012. Watering our cities: the capacity for water sensitive urban design to support urban cooling and improve human thermal comfort in the Australian context. Progress in Physical Geography 0309133312461032.

CRCWSC, 2014. Strategies for preparing robust business cases, CRCWSC Research Synthesis. CRC for Water Sensitive Cities: Melbourne, Australia.

DELWP, 2017. Victora Planning Provisions, In: Department of Environment, Land, Water and Planning (Ed.). Victoria State Government: Melbourne.

Department of Infrastructure, 1998. From Doughnut City to Café Society. Victorian Government: Melbourne.

Dietz, M.E., 2007. Low impact development practices: A review of current research and recommendations for future directions. Water, Air, and Soil Pollution 186(1-4) 351-363.

Dobbie, M., Green, R., 2013. Public perceptions of freshwater wetlands in Victoria, Australia. Landscape and Urban Planning 110 143-154.

Dolnicar, S., Hurlimann, A., Grün, B., 2011. What affects public acceptance of recycled and desalinated water? Water Research 45(2) 933-943. 
Domènech, L., Saurí, D., 2010. Socio-technical transitions in water scarcity contexts: Public

528 acceptance of greywater reuse technologies in the Metropolitan Area of Barcelona. Resources, Conservation and Recycling 55(1) 53-62.

DPCD, 2016. Victoria Planning Provisions, In: Department Department of Planning and Community Development (Ed.): Melbourne, Victoria.

Draper, N.R., Smith, H., 2014. Applied regression analysis. John Wiley \& Sons.

E2STORMED, 2015. Proceedings of the final conference. European Regional Development Fund: Turin (Italy).

EEA, 2006. Urban sprawl in Europe - The ignored challenge. European Environmental Agency. Ellis, J., Deutsch, J.-C., Mouchel, J.-M., Scholes, L., Revitt, M.D., 2004. Multicriteria decision approaches to support sustainable drainage options for the treatment of highway and urban runoff. Science of the total Environment 334 251-260.

539 Farrelly, M., Brown, R., 2011. Rethinking urban water management: Experimentation as a way 540 forward? Global Environmental Change 21(2) 721-732.

541 Ferguson, B.C., Brown, R.R., Frantzeskaki, N., de Haan, F.J., Deletic, A., 2013. The enabling institutional context for integrated water management: Lessons from Melbourne. Water Research 47(20) 7300-7314.

Fletcher, T.D., Shuster, W., Hunt, W.F., Ashley, R., Butler, D., Arthur, S., Trowsdale, S., Barraud, S., Semadeni-Davies, A., Bertrand-Krajewski, J.-L., 2014. SUDS, LID, BMPs, WSUD and more-The evolution and application of terminology surrounding urban drainage. Urban Water Journal 1-18. Fronteira, P., Kauhanen, P., Kunze, M., 2014. GreenPlanIT; LID Site Suitability Tool. Unpublished work.

Galster, G., Hanson, R., Ratcliffe, M.R., Wolman, H., Coleman, S., Freihage, J., 2001. Wrestling sprawl to the ground: defining and measuring an elusive concept. Housing policy debate 12(4) 681717.

Geertman, S., Stillwell, J., 2004. Planning support systems: an inventory of current practice.

Computers, Environment and Urban Systems 28(4) 291-310.

Green, O.O., Shuster, W.D., Rhea, L.K., Garmestani, A.S., Thurston, H.W., 2012. Identification and Induction of Human, Social, and Cultural Capitals through an Experimental Approach to Stormwater Management. Sustainability 4(8) 1669.

Hotelling, H., 1933. Analysis of a complex of statistical variables into principal components. Journal of educational psychology 24(6) 417.

Jenks, G.F., 1967. The data model concept in statistical mapping. International yearbook of cartography 7(1) 186-190.

Jin, Z., Sieker, F., Bandermann, S., Sieker, H., 2006. Development of a GIS-based expert system for on-site storm-water management. Water Practice \& Technology 1(01).

Lee, J.G., Selvakumar, A., Alvi, K., Riverson, J., Zhen, J.X., Shoemaker, L., Lai, F.-H., 2012. A watershed-scale design optimization model for stormwater best management practices. Environmental Modelling \& Software 37 6-18.

Loughnan, M., Tapper, N., Lynch, K., McInnes, J., Phan, T., 2012. A spatial vulnerability analysis of urban populations during extreme heat events in Australian capital cities. National Climate Change Adaptation Research Facility.

Lovell, S.T., Taylor, J.R., 2013. Supplying urban ecosystem services through multifunctional green infrastructure in the United States. Landscape ecology 28(8) 1447-1463.

Lundy, L., Wade, R., 2011. Integrating sciences to sustain urban ecosystem services. Progress in Physical Geography 35(5) 653-669.

Mahan, B.L., Polasky, S., Adams, R.M., 2000. Valuing Urban Wetlands: A Property Price Approach. Land Economics 76(1) 100-113.

Marlow, D.R., Moglia, M., Cook, S., Beale, D.J., 2013. Towards sustainable urban water management: A critical reassessment. Water Research 47(20) 7150-7161.

Martin, C., Ruperd, Y., Legret, M., 2007. Urban stormwater drainage management: The development of a multicriteria decision aid approach for best management practices. European Journal of Operational Research 181(1) 338-349. 
Mathey, J., Rößler, S., Banse, J., Lehmann, I., Bräuer, A., 2015. Brownfields As an Element of Green Infrastructure for Implementing Ecosystem Services into Urban Areas. Journal of Urban Planning and

McLoughlin, B., 1991. Urban consolidation and urban sprawl: a question of density.

Melbourne Water, 2005. WSUD Engineering Procedures: Stormwater: Stormwater, First ed. CSIRO PUBLISHING, Melbourne (Australia).

Melbourne Water, 2013. 10,000 Raingardens, Innovation at Melbourne Water. Melbourne Water: Melbourne.

Melbourne Water, 2017. Stormwater Factsheet: retrieved on 6/12/2017 from melbournewater.com.au. Mell, I.C., 2009. Can green infrastructure promote urban sustainability? Proceedings of the ICEEngineering Sustainability 162(1) 23-34.

Mitchell, V.G., Cleugh, H., 2006. Exploring the water balance, microclimate and energy usage benefits of water sensitive urban design, 7th Int. Conf. on Urban Drainage Modelling and 4th Int. Conf. on Water Sensitive Urban Design. Monash University: Melbourne, Australia, pp. 225-232. Montgomery, M.R., Gragnolati, M., Burke, K.A., Paredes, E., 2000. Measuring living standards with proxy variables. Demography $37(2)$ 155-174.

Myers, J.L., Well, A., Lorch, R.F., 2010. Research design and statistical analysis. Routledge. Netusil, N.R., Levin, Z., Shandas, V., Hart, T., 2014. Valuing green infrastructure in Portland, Oregon. Landscape and Urban Planning 124(Supplement C) 14-21.

Rijke, J.S., De Graaf, R.E., Van de Ven, F.H.M., Brown, R.R., Biron, D.J., 2008. Comparative case studies towards mainstreaming water sensitive urban design in Australia and the Netherlands, Proceedings of the 11th International Conference on Urban Drainage (ICUD), Edinburgh, Scotland. Rosenshein, L., Scott, L., 2011. Spatial Statistics Best Practices. Redlands, CA. USA: ESRI. Roy, A.H., Wenger, S.J., Fletcher, T.D., Walsh, C.J., Ladson, A.R., Shuster, W.D., Thurston, H.W., Brown, R.R., 2008. Impediments and solutions to sustainable, watershed-scale urban stormwater management: lessons from Australia and the United States. Environmental Management 42(2) 344359.

Schifman, L.A., Herrmann, D.L., Shuster, W.D., Ossola, A., Garmestani, A., Hopton, M.E., 2017. Situating Green Infrastructure in Context: A Framework for Adaptive Socio-Hydrology in Cities. Water Resources Research(53).

Scholz, M., 2006. Decision-support tools for sustainable drainage. Proceedings of the ICEEngineering Sustainability 159(3) 117-125.

Sharma, A.K., Cook, S., Tjandraatmadja, G., Gregory, A., 2012. Impediments and constraints in the uptake of water sensitive urban design measures in greenfield and infill developments. Water Science \& Technology 65(2) 340-352.

Shuster W.D., Morrison M.A., R., W., 2008. Front-loading urban stormwater management for success - a perspective incorporating current studies on the implementation of retrofit low-impact development. Cities and the Environment 1(2).

Steeneveld, G.J., Koopmans, S., Heusinkveld, B.G., Theeuwes, N.E., 2014. Refreshing the role of open water surfaces on mitigating the maximum urban heat island effect. Landscape and Urban Planning 121 92-96.

te Brömmelstroet, M., Bertolini, L., 2008. Developing land use and transport PSS: Meaningful information through a dialogue between modelers and planners. Transport Policy 15(4) 251-259. Thompson, S., Maginn, P., 2012. Planning Australia: an overview of urban and regional planning, Second ed. Cambridge University Press, Melbourne (Australia). UN Habitat, 2013. Streets as public spaces and drivers of urban prosperity. Nairobi: UN Habitat. Urich, C., Bach, P.M., Sitzenfrei, R., Kleidorfer, M., McCarthy, D.T., Deletic, A., Rauch, W., 2013. Modelling cities and water infrastructure dynamics. Proceedings of the ICE-Engineering Sustainability 166(5) 301-308.

Urrutiaguer, M., Rossrakesh, S., Potter, M., Ladson, A.R., Walsh, C.J., 2012. Using directly connected imperviousness mapping to inform stormwater management strategies, WSUD 2012: Water sensitive urban design; Building the water sensiitve community; 7th international conference on water sensitive urban design. Engineers Australia, p. 314. 
633 Viavattene, C., Scholes, L., Revitt, D.M., Ellis, J.B., 2008. A GIS based decision support system for 634 the implementation of stormwater best management practices, 11th International Conference on 635 Urban Drainage, Edinburgh, Scotland, UK.

636 Vonk, G., Geertman, S., Schot, P.P., 2005. Bottlenecks blocking widespread usage of planning 637 support systems. Environment and planning A 37(5) 909-924.

638 Walsh, C.J., Fletcher, T.D., Ladson, A.R., 2005. Stream restoration in urban catchments through 639 redesigning stormwater systems: looking to the catchment to save the stream. Journal of the North 640 American Benthological Society 24(3) 690-705.

641 Wong, T.H.F., Brown, R.R., 2009. The water sensitive city: principles for practice. Water Science \& 642 Technology 60(3) 673.

643 Woods Ballard, B., Kellagher, R., Martin, P., Jefferies, C., Bray, R., Shaffer, P., 2007. The SUDS 644 manual, First ed. Ciria, London. 


\section{Table of Tables}

645 Table 1 Factors selected for the spatial analysis of WSUD.

646 Table 2 Normalisation for distance to centre: correlation coefficients between socio-

647 economic factors and RW per urban ring .35

648 
Table 1 Factors selected for the spatial analysis of WSUD.

\begin{tabular}{|c|c|c|c|c|}
\hline & Name & Description & $\begin{array}{l}\text { Spatial } \\
\text { unit* }\end{array}$ & Source $* *$ \\
\hline \multirow{2}{*}{ Biophysical } & Slope & Slope of the surface [\%] & Location & VIC Data \\
\hline & Topography & Distance to natural waterways $[\mathrm{m}]$ & Location & VIC Data \\
\hline \multirow{9}{*}{$\begin{array}{l}\text { Socio- } \\
\text { Economic }\end{array}$} & $\begin{array}{l}\text { Age of } \\
\text { development }\end{array}$ & $\begin{array}{l}\text { Time since first development in an area } \\
\text { [years] }\end{array}$ & Suburb & $\begin{array}{l}\text { Melbourne } \\
\text { Museum }\end{array}$ \\
\hline & $\begin{array}{l}\text { Population } \\
\text { Density }\end{array}$ & Permanent residents from census $\left[\mathrm{p} / \mathrm{km}^{2}\right]$ & Suburb & ABS \\
\hline & House price & $\begin{array}{l}\text { Median price of house sales in } 2014 \\
\text { [AU\$] }\end{array}$ & Suburb & DELWP \\
\hline & Education Level & $\begin{array}{l}\text { Proxy: People holding a bachelor degree } \\
\text { [fraction] }\end{array}$ & Suburb & ABS \\
\hline & $\begin{array}{l}\text { Environmental } \\
\text { Awareness }\end{array}$ & $\begin{array}{l}\text { Proxy: First preference votes for 'The } \\
\text { Greens' in } 2002 \text { and } 2010 \text { federal elections } \\
\text { [fraction] }\end{array}$ & $\begin{array}{l}\text { Electoral } \\
\text { district }\end{array}$ & VEC \\
\hline & $\begin{array}{l}\text { Sense of } \\
\text { Community }\end{array}$ & $\begin{array}{l}\text { Proxy: People engaging in voluntary work } \\
\text { for a local organisation or group [fraction] }\end{array}$ & Suburb & ABS \\
\hline & $\begin{array}{l}\text { Heat } \\
\text { vulnerability }\end{array}$ & $\begin{array}{l}\text { Ordinal index ranging from 1-10 (low- } \\
\text { high vulnerability) }\end{array}$ & Postcode & $\begin{array}{l}\text { Loughnan } \\
\text { et al. }(2012)\end{array}$ \\
\hline & IRSAD & $\begin{array}{l}\text { Index of Relative Socio-economic } \\
\text { Advantage and Disadvantage. Ordinal } \\
\text { index with arbitrary scale. }\end{array}$ & Suburb & ABS \\
\hline & IER & $\begin{array}{l}\text { Index of Economic Resources. Relative } \\
\text { indicator. Ordinal index with arbitrary } \\
\text { scale }\end{array}$ & Suburb & ABS \\
\hline \multirow{2}{*}{ Urban form } & Land use & $\begin{array}{l}\text { Two types of land-use classifications: by } \\
\text { the Victorian government and adapted } \\
\text { from Victorian zoning regulations. }\end{array}$ & Location & $\begin{array}{l}\text { VIC Data; } \\
\text { Bach et al. } \\
(2015)\end{array}$ \\
\hline & $\begin{array}{l}\text { Distance to } \\
\text { centre }\end{array}$ & $\begin{array}{l}\text { Distance to Melbourne's geographic centre } \\
\text { [km] (centroid of the four inner councils } \\
\text { according to Buxton \& Tieman }(2005))\end{array}$ & Suburb & Calculated \\
\hline
\end{tabular}

*The smallest spatial unit of the source data.

**VIC Data: government data repository for the state of Victoria, accessed through www.data.vic.gov.au. Melbourne Museum: unpublished dataset from May 2015. ABS: Australian Bureau of Statistics, census data 2011, accessed through www.abs.gov.au. DELWP: Victoria Department of Environment, Land, Water and Planning, accessed through www.delwp.vic.gov.au. VEC: Victorian Electoral Commission, accessed through www.vec.vic.gov.au. 
Table 2 Normalisation for distance to centre: correlation coefficients between socio-economic factors and RW per urban ring

\begin{tabular}{|c|c|c|c|c|c|c|c|c|c|c|}
\hline \multirow{2}{*}{ Factor } & \multicolumn{2}{|c|}{ Centre } & \multicolumn{2}{|c|}{$\begin{array}{c}\text { Inner } \\
\text { Suburbs }\end{array}$} & \multicolumn{2}{|c|}{$\begin{array}{l}\text { Middle } \\
\text { Suburbs }\end{array}$} & \multicolumn{2}{|c|}{ Outer Suburbs } & \multicolumn{2}{|c|}{ Fringe } \\
\hline & $\begin{array}{l}\text { Corr. } \\
\text { Coeff. }\end{array}$ & $p^{*}$ & $\begin{array}{l}\text { Corr. } \\
\text { Coeff. }\end{array}$ & $p^{*}$ & $\begin{array}{l}\text { Corr. } \\
\text { Coeff. }\end{array}$ & $p^{*}$ & $\begin{array}{l}\text { Corr. } \\
\text { Coeff. }\end{array}$ & $p^{*}$ & $\begin{array}{l}\text { Corr. } \\
\text { Coeff. }\end{array}$ & $p^{*}$ \\
\hline Age of development & - & - & - & - & - & - & - & 0.01 & - & - \\
\hline Population Density & - & - & - & - & - & - & - & - & - & - \\
\hline House Price & - & - & - & - & - & - & - & - & - & - \\
\hline Education Level & - & - & - & - & - & - & - & - & - & - \\
\hline Environmental Awareness & 0.346 & 0.01 & - & - & - & - & - & - & -0.318 & 0.043 \\
\hline Sense of Community & - & - & - & - & - & - & -0.405 & 0.001 & -0.430 & 0.005 \\
\hline Heat Vulnerability & - & - & - & - & - & - & - & - & - & - \\
\hline IRSAD & - & - & - & - & - & - & - & - & - & - \\
\hline IER & - & - & - & - & - & - & - & - & - & - \\
\hline
\end{tabular}

*Only significant correlations (p-value of 0.05 or below) are shown in the table. 


\section{Appendix A}

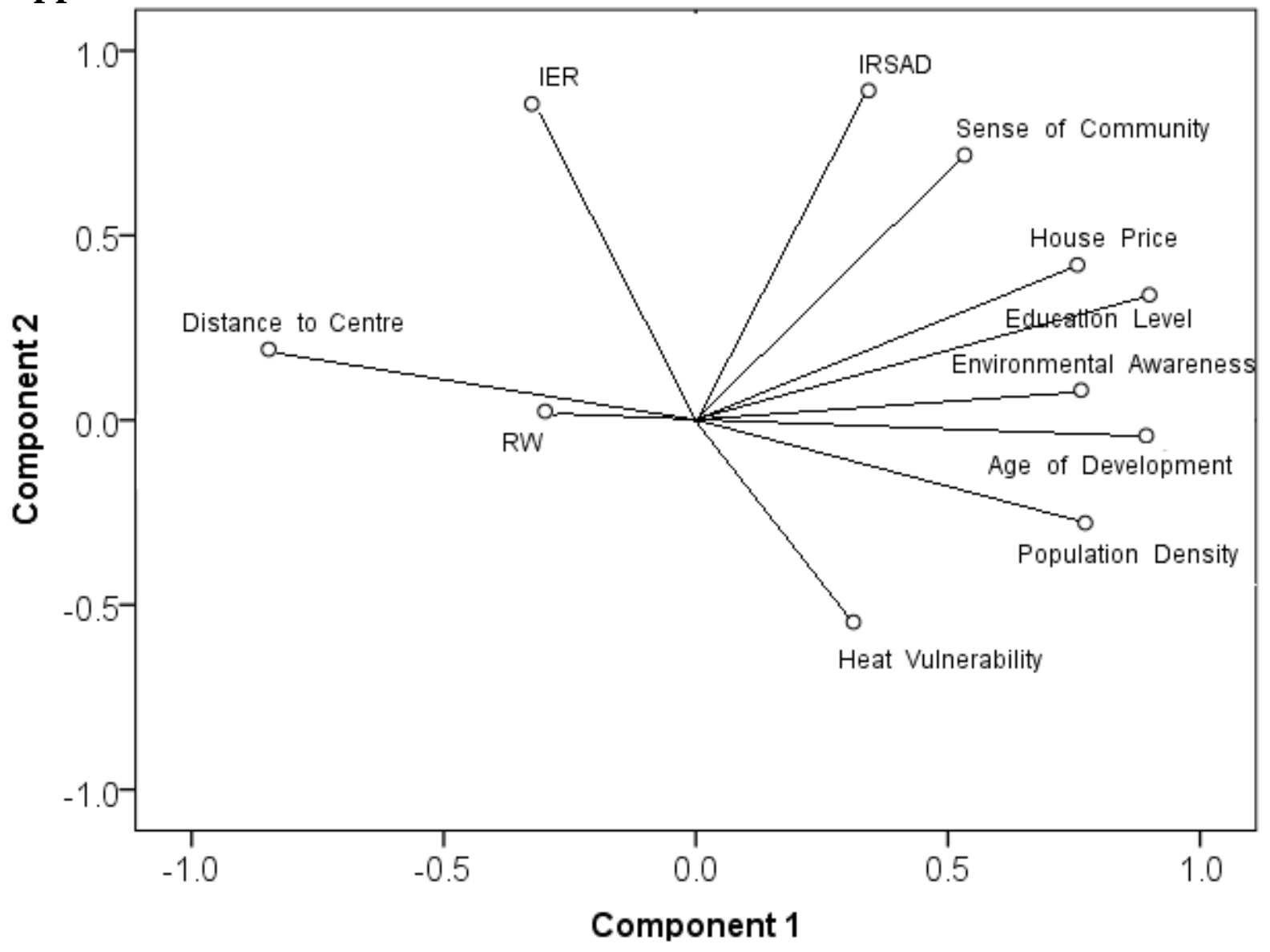

Figure A.1 Component plot in rotated space. 